\title{
Effects of Active Gases on Droplet Transfer and Weld Morphology in Pulsed-Current NG-GMAW of Mild Steel
}

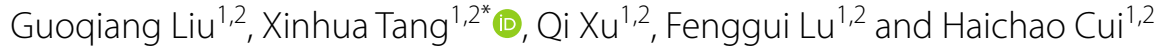

\begin{abstract}
The current research of narrow-gap gas metal arc welding (NG-GMAW) primarily focuses on improving the sidewall fusion and avoiding the lack-of-fusion defect. However, the high cost and operation difficulty of the methods limit the industrial application. In this study, small amount of active gases $\mathrm{CO}_{2}$ and $\mathrm{O}_{2}$ were added into pure argon inert shielding gas to improve the weld formation of pulsed-current narrow-gap gas metal arc welding (NG-GMAW) of mild steel. Their effects on droplet transfer and arc behavior were investigated. A high-speed visual sensing system was utilized to observe the metal transfer process and arc morphology. When the proportion of $\mathrm{CO}_{2}$, being added into the pure argon shielding gas, changes from $5 \%$ to $25 \%$, the metal transfer mode changes from pulsed spray streaming transfer to pulsed projected spray transfer, while it remains the pulsed spray streaming transfer when $2 \%$ to $10 \% \mathrm{O}_{2}$ is added. Both $\mathrm{CO}_{2}$ and $\mathrm{O}_{2}$ are favorable to stabilizing arc and welding process. $\mathrm{O}_{2}$ is even more effective than $\mathrm{CO}_{2}$. However, $\mathrm{O}_{2}$ is more likely to cause slags on the weld surface, while $\mathrm{CO}_{2}$ can improve the weld appearance in some sense. The weld surface concavity in NG-GMAW is greatly influenced by the addition of active gas, but the weld width and weld penetration almost keep constant. This study proposes a new method which is beneficial to improving the weld bead formation and welding process stability.
\end{abstract}

Keywords: Metal transfer, Active gases, Pulsed-current NG-GMAW, Weld morphology

\section{Introduction}

Thick and large structural components are widely applied in various fields, such as offshore drilling platforms, shipbuilding, high-pressure vessels, and nuclear industry. Narrow-gap gas metal arc welding (NG-GMAW) is a preferential technology in manufacturing such components owing to its great advantages, such as less filler metal, higher productivity, low heat input and minimal welding distortion $[1,2]$. However, the lack-of-fusion is the most common defect in NG-GMAW joints [3]. To improve the weld formation of NG-GMAW, plentiful progressive approaches have been put forward. He et al.

\footnotetext{
*Correspondence: xhtang@sjtu.edu.cn

1 Shanghai Key Laboratory of Materials Laser Processing and Modification, School of Materials Science and Engineering, Shanghai Jiao Tong University, Shanghai 200240, China

Full list of author information is available at the end of the article
}

adopted a swing arc method to the narrow-gap welding and reported that the swing arc had a great influence on the weld formation and sidewall fusion [4]. Increasing the arc swing frequency and amplitude contributed to increasing the surface concavity and sidewall penetration. In addition, Zhu et al. showed that the high arc-swing frequency and amplitude made more heat transferred to the sidewalls, beneficial to achieving a more symmetric weld bead and reducing the pores in the bead [5]. Duan et al. carried out the rotating arc NG-GMAW by a hollow draft motor and curved contact tube [6]. They indicated that too large sidewall stay time could result in the lack-of-fusion defect and large rotation angular velocity could avoid the overlap defect. Wang et al. developed an alternating magnetic field to assist the arc welding in narrow groove, and successfully obtained a larger sidewall penetration with a magnetic flux density up to $6 \mathrm{mT}[7]$. 
Besides, laser-arc hybrid welding and tandem GMAW are also commonly utilized in narrow gap welding processed to eliminate the lack-of-fusion defect and improve the weld formation [8-11].

All of these methods mentioned above can improve the weld bead formation but need specially designed welding torches or additional equipment, which means more investment. It is of great significance to exploit a costeffective method to improve the weld formation of NGGMAW. As is known, shielding gas is a significant factor influencing the GMAW process. Argon is the most commonly used shielding gas in arc welding, since it has no reaction with the molten metal. However, it may cause arc instability and low wettability [12]. To achieve better joint performances, varieties of mixtures with inert and active gases were developed. Zhang et al. studied the influence of shielding gases on the weld shape of a hybrid welding [13]. It was reported that the weld bead formation was improved first and then worsened and the weld penetration increased with the $\mathrm{CO}_{2}$ content in pure $\mathrm{Ar}$ increasing from $0 \%$ to $100 \%$. Huang reported that adding nitrogen into an argon-based shielding gas would increase the heat input [14]. Both the weld penetration and weld area increased with increase of nitrogen in argon-based shielding gas. Moreover, it was reported that the pores in the laser welds could be eliminated by using $\mathrm{N}_{2}$ as the shielding gases [15]. Zong et al. studied the influence of shielding gas on undercut defects in GMAW and found that the undercut defects could be significantly reduced by increasing the $\mathrm{CO}_{2}$ content [16]. However, when the $\mathrm{CO}_{2}$ content was higher than $20 \%$, welding spatters occurred frequently on the weld bead surface. The variation of weld bead formation is attributed to that the shielding gas directly determines the arc behavior and surface tension which influence the metal transfer and fluid flow in the welding pool [17-19]. Cai et al. evaluated the effect of ternary mixtures of $\mathrm{Ar}+\mathrm{He}+\mathrm{CO}_{2}$ on metal transfer in narrow-gap tandem GMAW. The results revealed that the metal transfer always remained a pulsed spray transfer when $\mathrm{CO}_{2}$ was kept at $10 \%$, no matter how the helium content varied in a certain range [20]. Zhao et al. found that decreasing the $\mathrm{CO}_{2}$ content in $\mathrm{Ar}+\mathrm{CO}_{2}+\mathrm{O}_{2}$ led to a wider arc and a stable pulsed streaming spray in pulsed GMAW [21]. Similar results were also reported by Wong at al. [22].

The current research effort of NG-GMAW mainly focuses on improving the sidewall fusion and avoiding the lack-of-fusion defect. However, the methods proposed are not widely available due to the high cost for developing a reliable suitable narrow-gap GMAW torch and its related equipment. A proper selection of shielding gases can be an economical effective way to solve this problem, however the related studies are less reported in
NG-GMAW. In this research, a series of welding experiments were carried out to evaluate the effects of varied gas compositions on the arc behaviors, metal transfer, welding process stability and weld morphology in pulsed current NG-GMAW of ferrous metal.

\section{Experimental Procedure}

Figure 1(a) briefly shows the schematic diagram of welding experiment system setup, in which a new-designed narrow-gap GMAW torch was applied. A high-speed video camera was used to observe arc profile and droplet transfer process. Its frame rate was $3000 \mathrm{fps}$ and the exposure time was $1.0 \mu \mathrm{s}$. The viewing direction was parallel to the welding direction and the distance from the camera lens to the filler wire tip was about $0.5 \mathrm{~m}$. An optical filter was used to block the arc light while capturing the droplet transfer process. The waveforms of welding current and arc voltage were detected by hall sensors and were sampled by a data acquisition system (DAS). Its sampling rate was $20 \mathrm{kHz}$. The welding experiments were conducted on the specimens of commercial quality hot-rolled steel Q345d, and ER50-6 wire with a diameter of $1.2 \mathrm{~mm}$ was used as filler metal. Their chemical compositions are given in Table 1. A 'simulated' narrowgap workpiece was used with the dimension of $100 \mathrm{~mm}$ (length) $\times 40 \mathrm{~mm}$ (width) $\times 35 \mathrm{~mm}$ (height) with a groove as shown in Figure 1(b). It was simple but suitable for observing the metal transfer and arc behaviors. A power source working in direct-current electrode positive (DCEP) was applied to welding process, which was set in single pulse mode, as shown in Figure 1(c). Different kinds of shielding gases were adopted, which are mainly the mixtures of argon and $\mathrm{CO}_{2}$ or $\mathrm{O}_{2}$ respectively. The $\mathrm{CO}_{2}$ content varied from $5 \%$ to $25 \%$ in the gas mixtures of $\mathrm{Ar}+\mathrm{CO}_{2}$, while the $\mathrm{O}_{2}$ content changed from $2 \%$ to $10 \%$ in the gas mixtures of $\mathrm{Ar}+\mathrm{O}_{2}$. The gas flow-rates through the external shielding gas hood and the nozzle of welding torch were both $30 \mathrm{~L} / \mathrm{min}$ with the total gas flow rate of $60 \mathrm{~L} / \mathrm{min}$. The welding current was $350 \mathrm{~A}$, the arc voltage was $34 \mathrm{~V}$, and the travelling speed was $300 \mathrm{~mm} /$ $\mathrm{min}$. The wire extension was about $15 \mathrm{~mm}$.

For investigation of welding process in a deep and narrow groove with varied gas mixtures, only the first pass of weld bead was deposited on each specimen. After welding, all the specimens were cut along the transverse direction of welding bead. Each specimen was polished and then was etched with $4 \%$ Nital solutions ( $4 \%$ nitric acid in alcohol). The weld bead was characterized by weld width $(\mathrm{W})$, weld penetration $(\mathrm{H})$ and weld surface concavity $(C)$ for evaluating the influence of varied gas mixtures on the weld morphology, as shown in Figure 1(d). In addition, the arc shape was also characterized by arc width and arc length. 

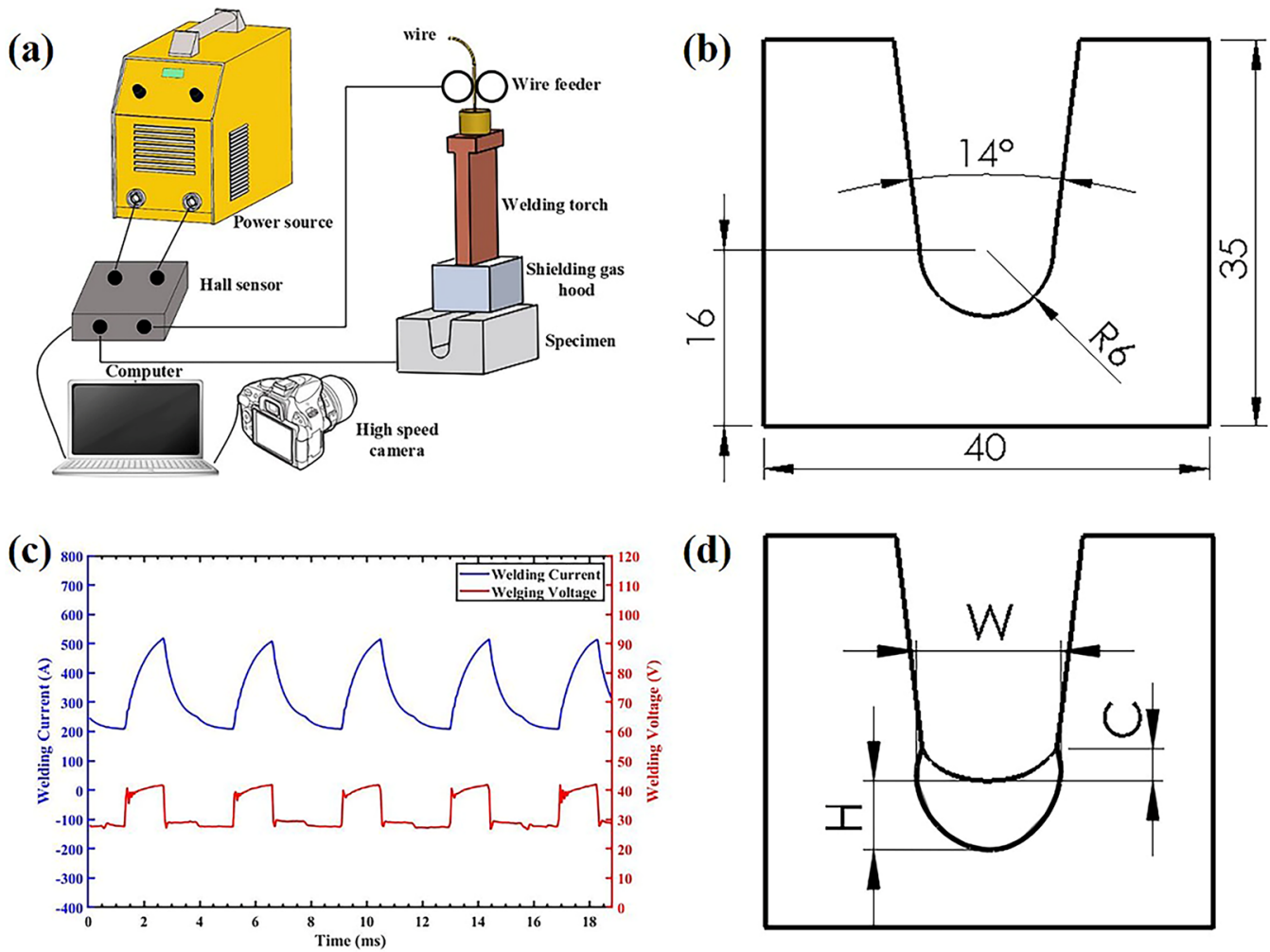

Figure 1 a Schematic diagram of welding experiment system setup, $\mathbf{b}$ cross section dimension of specimen and its narrow-gap groove, $\mathbf{c}$ Welding current and arc voltage waveforms, $\mathbf{d}$ characterization for first-pass weld bead of NG-GMAW

Table 1 Nominal chemical compositions of base metal and filler metal (wt \%)

\begin{tabular}{llllllllllllll}
\hline Material & $\mathbf{M n}$ & $\mathbf{S i}$ & $\mathbf{N i}$ & $\mathbf{C r}$ & $\mathrm{Ti}$ & $\mathbf{A l}$ & $\mathbf{V}$ & $\mathbf{S}$ & $\mathbf{P}$ & Mo & $\mathrm{Cu}$ & $\mathbf{C}$ & $\mathrm{Fe}$ \\
\hline Q345D & 1.45 & 0.27 & 0.07 & 0.05 & 0.05 & 0.02 & 0.01 & 0.01 & - & - & - & $\leq 0.18$ & Bal. \\
ER50-6 & $1.40-1.85$ & $0.80-1.15$ & $\leq 0.15$ & $\leq 0.15$ & - & - & $\leq 0.15$ & $\leq 0.025$ & $\leq .025$ & $\leq 0.15$ & $\leq 0.5$ & $0.06-0.15$ & Bal. \\
\hline
\end{tabular}

\section{Results and Discussion}

\subsection{Arc Shape and Metal Transfer}

Figure 2 presents the variation of arc profile under shielding of gas mixtures with varied $\mathrm{CO}_{2}$ content. It indicates that the arc shape experiences large changes with increased $\mathrm{CO}_{2}$ content. When the $\mathrm{CO}_{2}$ content in the shielding gas is $5 \%$, the arc extends even to the sidewalls of groove, which signifies that more heat is transmitted to the sidewalls and the welding pool is enlarged. The arc experiences a fluctuation in the range of welding current from base to peak. The fluctuation of arc is consistent with the current variation. The arc is cone-shaped at the base current, and bell-shaped with the arc edge upward warped at the peak current. The upward warp of arc mainly results from the restrain effect of narrow gap groove. The arc profiles under shielding gas of $\mathrm{Ar}+5 \% \mathrm{CO}_{2}$ and $\mathrm{Ar}+10 \% \mathrm{CO}_{2}$ are correspondingly similar at both base and peak current. However, when the $\mathrm{CO}_{2}$ content in the shielding gas is $25 \%$, the arc keeps the same conical shape through the whole pulse cycle, except for the change of its size.

The effect of $\mathrm{O}_{2}$ on the arc profile is shown in Figure 3. When the $\mathrm{O}_{2}$ content in the shielding gas is $2 \%$, the arc profile changes greatly comparing to that of any other gas mixtures mentioned above. The arc looks much like cone shape at the peak current, but slender bell-like shape at the base current. When $\mathrm{O}_{2}$ is added up to $5 \%$ and $10 \%$, the arc turns to be conical shape at the base current, and bell shape at the peak current, which is similar to that of gas mixtures with $5 \%$ or $10 \%$ $\mathrm{CO}_{2}$ contents. As shown in Figures 2 and 3, in comparison with conventional GMAW, the sidewalls of narrow 


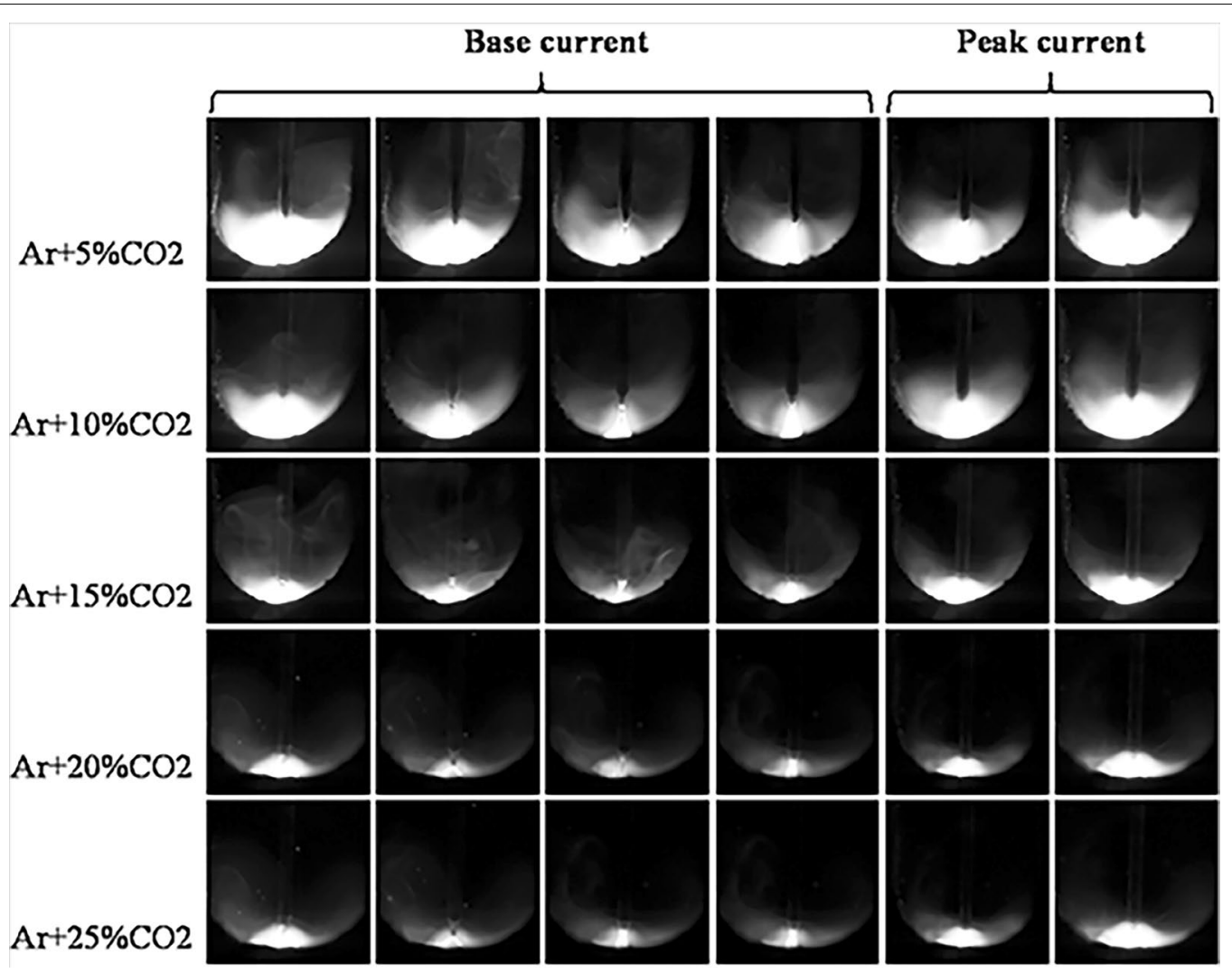

Figure 2 Variations of arc profile under shielding of gas mixtures with varied $\mathrm{CO}_{2}$ contents

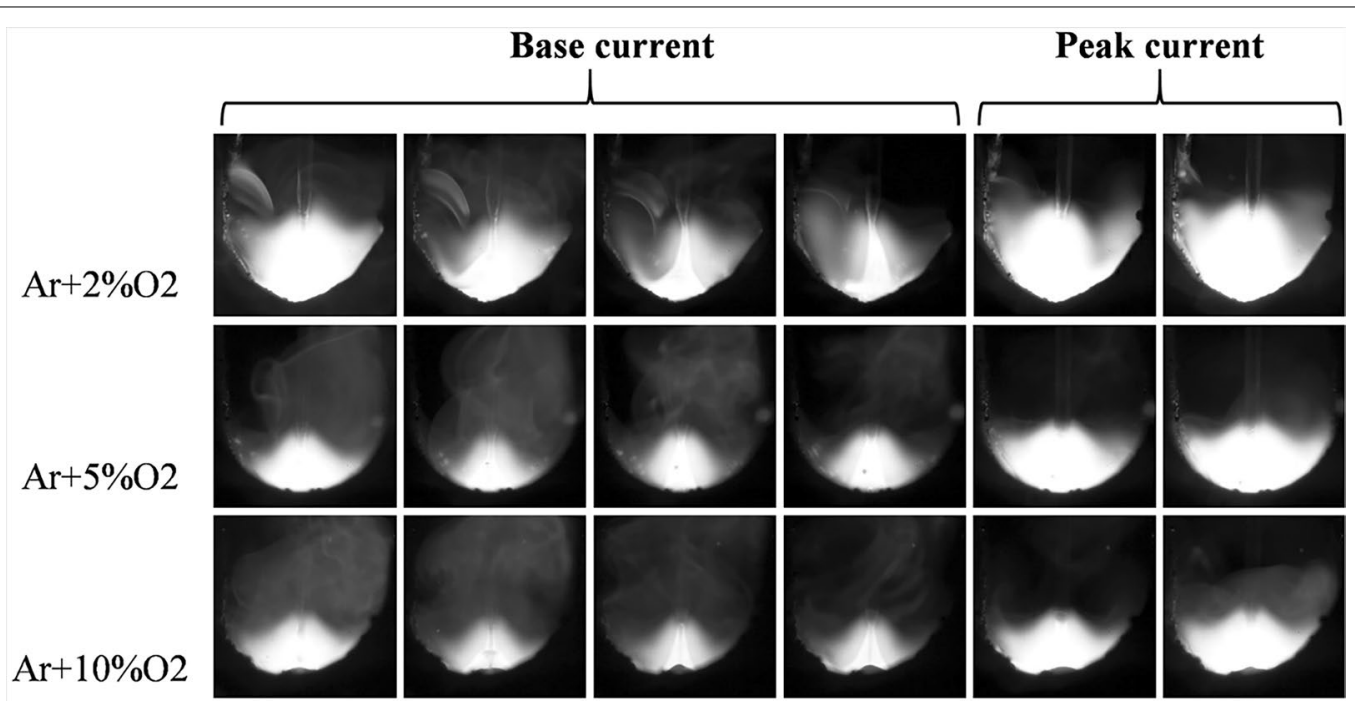

Figure 3 Variations of arc profile under shielding of gas mixtures with varied $\mathrm{O}_{2}$ contents

gap groove have strong restraint on the welding arc. The arc could not extend freely, and has no choice but to climb up when touching the sidewalls.
The detailed arc profile characteristics such as arc length, arc width and arc area at the peak current for varied contents of $\mathrm{CO}_{2}$ and $\mathrm{O}_{2}$ in shielding gas are displayed in Figure 4(a) and (b) separately. An overall tendency is 

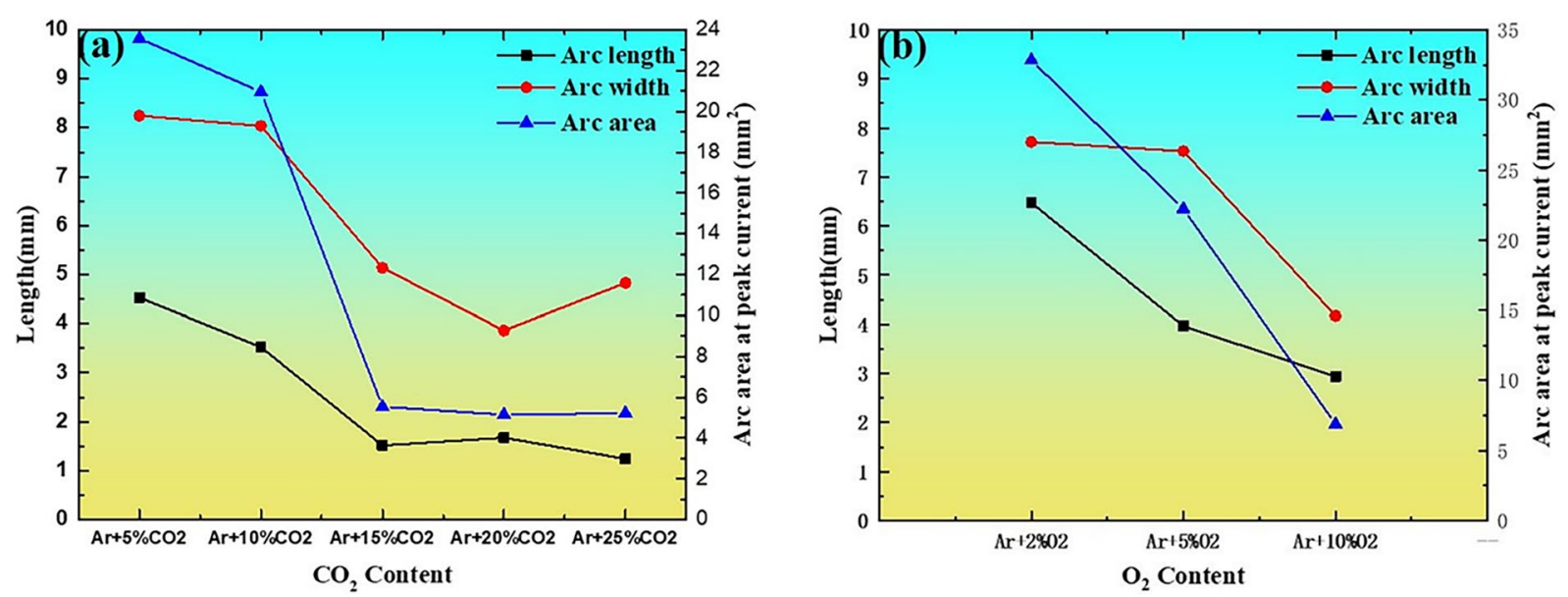

Figure 4 Variations of arc length, arc width and arc area under shielding of gas mixtures with (a) varied $\mathrm{CO}_{2}$ contents, and $(\mathbf{b})$ varied $\mathrm{O}_{2}$ contents

Table 2 Chemical and physical properties of gases used in pulsed current NG-GMAW

\begin{tabular}{lllll}
\hline $\begin{array}{l}\text { Shielding } \\
\text { gas }\end{array}$ & $\begin{array}{l}\text { Density at } \\
\mathbf{1 5}{ }^{\circ} \mathbf{C} \\
\mathbf{1} \text { bar }(\mathbf{k g} / \\
\left.\mathbf{m}^{\mathbf{3}}\right)\end{array}$ & $\begin{array}{l}\text { Dissociation } \\
\text { energy }(\mathbf{e V} / \\
\text { molecule) }\end{array}$ & $\begin{array}{l}\text { First } \\
\text { ionization } \\
\text { energy }(\mathbf{e V} / \\
\text { molecule) }\end{array}$ & $\begin{array}{l}\text { Chemical } \\
\text { activity }\end{array}$ \\
\hline $\mathrm{Ar}$ & 1.669 & 0 & 15.8 & Inert \\
$\mathrm{CO}_{2}$ & 1.849 & 4.3 & 14.4 & Oxidizing \\
$\mathrm{O}_{2}$ & 1.337 & 5.1 & 13.6 & Oxidizing \\
\hline
\end{tabular}

that all of them fall off with the increase of $\mathrm{CO}_{2}$ or $\mathrm{O}_{2}$. On the one hand, both $\mathrm{CO}_{2}$ and $\mathrm{O}_{2}$ are active gases, which is beneficial to stabilizing the cathode spot and obtaining a stable arc combustion when proper contents of them are added into the pure argon.

On the other hand, the temperature of arc edge is approximately $10000 \mathrm{~K}$, where the thermal conductivity of $\mathrm{O}_{2}$ is $1.21 \mathrm{~W} / \mathrm{m} \cdot \mathrm{K}$ while the thermal conductivity of pure argon is only $0.66 \mathrm{~W} / \mathrm{m} \cdot \mathrm{K}$ presented by Murphy et al. [23]. Wang et al. reported that the thermal conductivity of $\mathrm{CO}_{2}$ is $1.47 \mathrm{~W} / \mathrm{m} \cdot \mathrm{K}$ at the same temperature [14]. Therefore, when proper small amount of $\mathrm{CO}_{2}$ or $\mathrm{O}_{2}$ is added into the pure argon, the thermal conductivity of arc gets higher, which results in more uniform heat distribution and expansion of arc. However, much higher content of $\mathrm{CO}_{2}$ also means more heat loss by conduction of arc because of its higher thermal conductivity. Meanwhile, $\mathrm{CO}_{2}$ and $\mathrm{O}_{2}$ are polyatomic molecules and need to be dissociated firstly before ionizing, as shown in Table 2, which means more energy needs to be consumed to ignite the arc. In addition, the decomposition and ionization of $\mathrm{CO}_{2}$ will generate more ions to increase the arc electric field intensity, which results in increased electromagnetic force. When the $\mathrm{CO}_{2}$ or $\mathrm{O}_{2}$ content in the shielding gas gets higher, the thermal pinch effect together with increased electromagnetic force constricts the arc, and the arc gets difficult to expand.

In light of above analysis, the shielding gas composition has a great impact on arc shape and its stability. Actually, it also plays a key role in metal transfer process of welding. When the shielding gas is changed to $\mathrm{Ar}+5 \% \mathrm{CO}_{2}$ or $\mathrm{Ar}+10 \% \mathrm{CO}_{2}$, the metal transfer has similar features at same pulsed-current. Figure 5 presents the pulse streaming spray transfer in welding with both shielding gas mixtures. The wire tip turns to be a tapered shape that represents a typical feature for streaming spray transfer. It is encircled by the arc, and is adequately heated to become plastic. As a result, a slender long molten neck hanging on the wire tip is formed and directs towards the weld pool. At the wire tip, a droplet with the diameter closing to the wire diameter is transferred from a cone-shaped wire tip into the welding pool in spray way. In addition, the arc jumping phenomenon along with the long neck is also observed in Figure 5, and the current at this moment is defined as the transition current of streaming spray transfer.

In pulsed streaming transfer process, it can be seen that a plenty of small spatters are produced in the shielding gas mixture of $\mathrm{Ar}+5 \% \mathrm{CO}_{2}$ as shown in Figure 5(a). This is owing to the relatively long arc in $\mathrm{Ar}+5 \% \mathrm{CO}_{2}$, which means lower arc stiffness. It brings about arc fluctuation, and thus the force balance of the radial component of the electromagnetic force is easy to be broken. One more to note is the arc jumping phenomenon which took place at $t+2.67 \mathrm{~ms}$ and $t+4 \mathrm{~ms}$ as shown in Figure 5(a). The arc root is firstly located at the bottom of neck as shown in Figure 6(a), and gradually climbs to the top of the neck which becomes longer and thinner as shown in Figure 6(b). At the same time, the arc also 

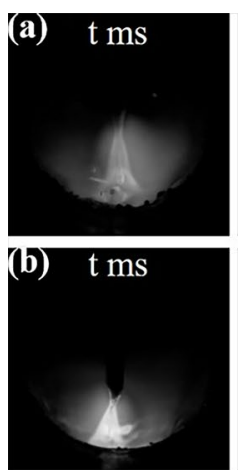
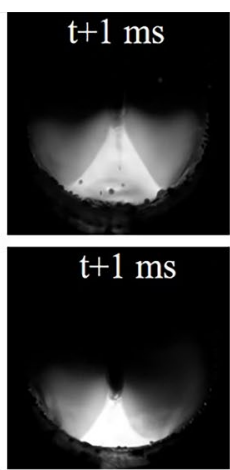
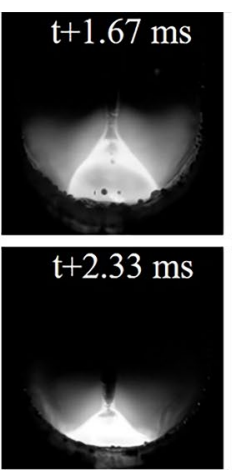
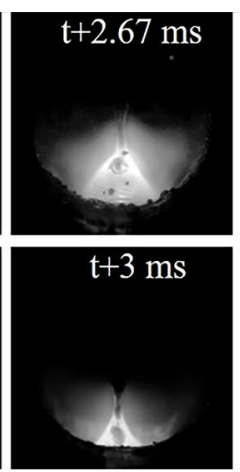
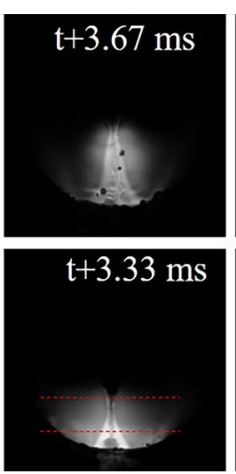

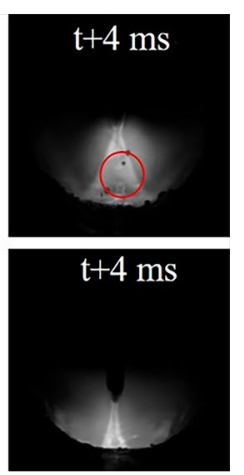

Figure 5 Metal transfer process under shielding of gas mixtures of (a) $\mathrm{Ar}+5 \% \mathrm{CO}_{2}(\mathbf{b}) \mathrm{Ar}+10 \% \mathrm{CO}_{2}$

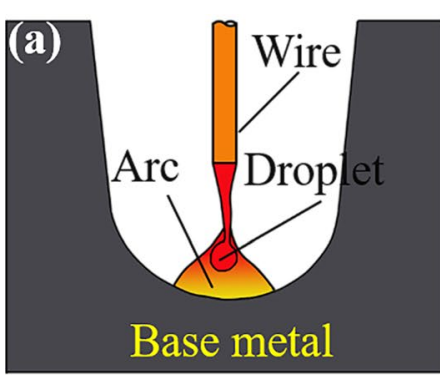

$F_{a}$ : anode-spot pressure

$F_{e m}$ : electromagnetic force

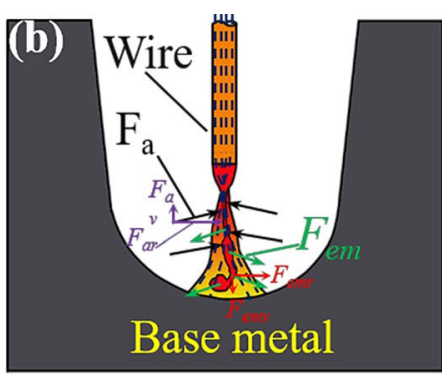

$F_{a r}$ : radial component of $\mathrm{F}_{\mathrm{a}}$

$F_{e m r}$ radial component of $\mathrm{F}_{\mathrm{em}}$

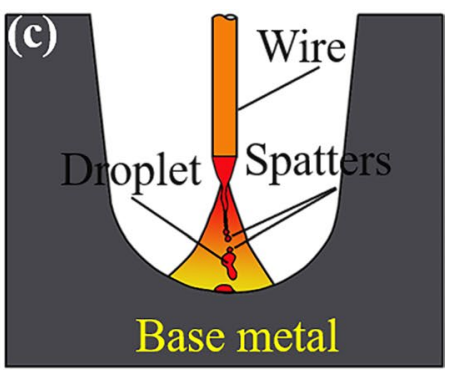

$F_{a v}$ : vertical component of $\mathrm{F}_{\mathrm{a}}$

$F_{e m v}$ : vertical component of $\mathrm{F}_{\mathrm{em}}$

Figure $\mathbf{6}$ Schematic illustration of arc jumping phenomenon: $\mathbf{a}$ arc surrounding the bottom of droplet, $\mathbf{b}$ force analysis when arc climbs to the top of neck, c droplet transfer after arc jumping

changes to conical shape. The longer and thinner neck is surrounded and directly heated by the arc, and thus leads to a large anode-spot pressure acting on the thinner neck. Under the combined action of the anode-spot pressure and unbalanced electromagnetic force, the neck gets unstable. Under this condition, when the droplet is transferred to welding pool, the neck is broken at one point on the neck rather than on the wire tip. This causes the generation of small droplets, which ultimately form spatters rather than are transferred into the welding pool (as shown in Figure 6(c)).

With $\mathrm{CO}_{2}$ increasing to $15 \%$, it can be observed in Figure 7(a) that the neck is shorter than that in the shielding gas mixture of $\mathrm{Ar}+5 \% \mathrm{CO}_{2}$ or $\mathrm{Ar}+10 \% \mathrm{CO}_{2}$ as shown in Figure 5 , the metal is transferred in projected spray-like transfer mode. When $\mathrm{Ar}+20 \% \mathrm{CO}_{2}$ or $\mathrm{Ar}+25 \% \mathrm{CO}_{2}$ is applied, the metal is transferred in projected spray transfer mode as shown in Figure 7(b) and (c), in which a droplet diameter is roughly equal to the wire tip diameter.

When the $\mathrm{CO}_{2}$ content is relatively low (5\% or $10 \%$ ), the energy for arc ignition is just a little higher than that in the pure argon, and so is the heat loss because of its high thermal conductivity. However, when $\mathrm{CO}_{2}$ content increases up to $25 \%$, the thermal conductivity gets great improvement, consequently, the heat loss increases sharply, and so does the energy for arc ignition. Moreover, the variation of arc behavior mentioned above also have a great impact. The arc just hangs on the droplet without climbing up to the wire. Consequently, the energy for heating the wire tip is not enough to form a streaming.

The droplet transfer mode is apparently influenced by different arc behaviors under varied shielding gases, and it is virtually influenced by the force distribution on the droplet. The force balance theory claims that a droplet will detach from the electrode tip when the detaching forces exceed the retention forces.

Generally, four different forces are considered in the metal transfer of arc welding. The surface tension is a retention force, while the gravity, the plasma drag force and the electromagnetic force are detaching forces. Nemchinsky [24] prosposed that the drag force is not important during droplet transfer process at high currents. According to Scotti et al. [25], the electromagnetic force is the governing force during both projected spray and streaming spray transfer, and its induced pinch effect 

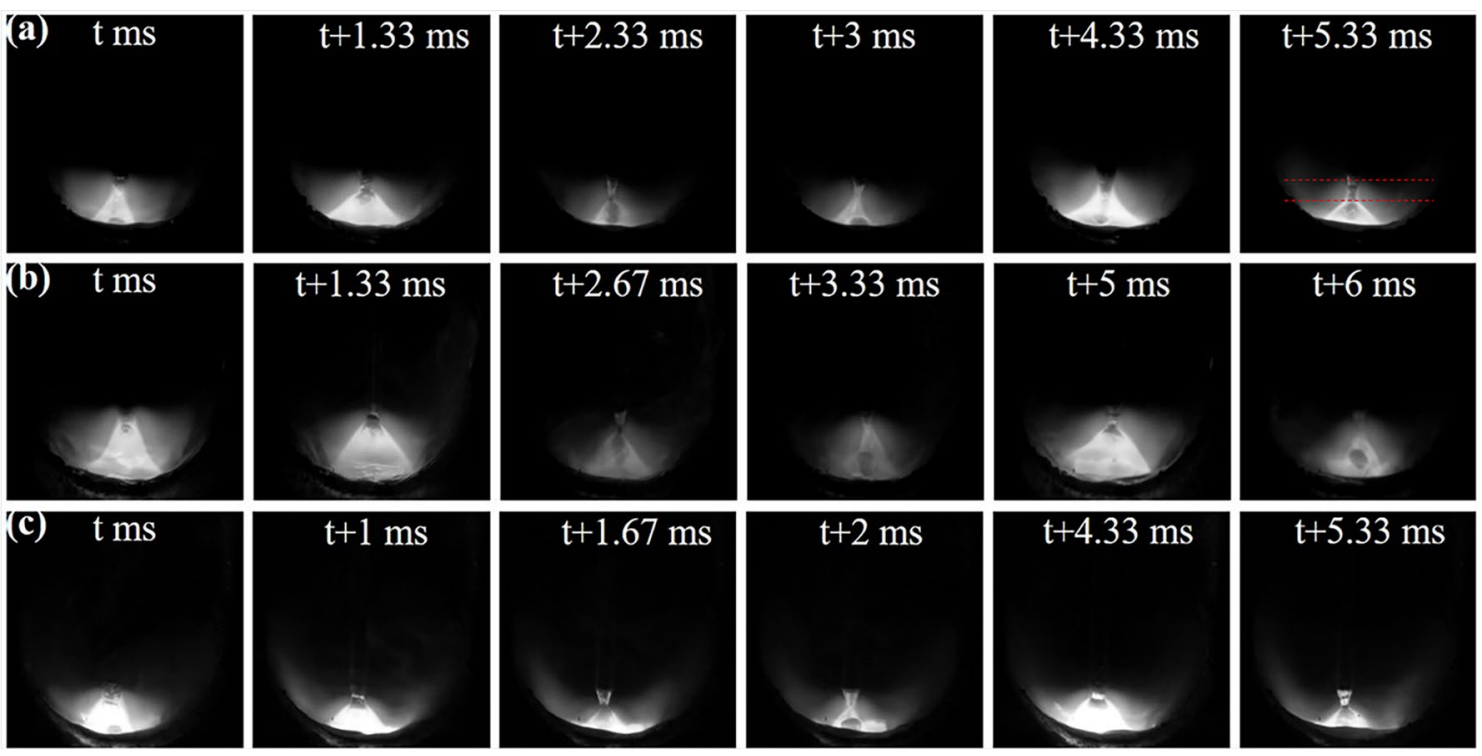

Figure 7 Metal transfer process under shielding of gas mixtures of (a) $\mathrm{Ar}+15 \% \mathrm{CO}_{2}, \mathbf{b} \mathrm{Ar}+20 \% \mathrm{CO}_{2}, \mathbf{c ~} \mathrm{Ar}+25 \% \mathrm{CO}_{2}$

limits the droplet. So more attention is put on surface tension and electromagnetic force.

The gravity $F_{g}$ in flat position welding is given by Kim and Eagar as below [26]:

$$
F_{g}=4 / 3 \pi r_{d}^{2} \rho_{d} g
$$

where $r_{d}$ is the droplet radius, $\rho_{d}$ is the mass density of the droplet, and $g$ is the gravitational acceleration. The surface tension can be expressed as follows:

$$
F_{\gamma}=2 \pi R_{e} \gamma,
$$

where $R_{e}$ is the radius of the electrode and $\gamma$ is the surface tension coefficient of the liquid metal, which is significantly influenced by the $\mathrm{O}_{2}$ content in a binary Fe-O system according to Sahoo et al. [27].

The plasma drag force on the droplet is given by [28]:

$$
F_{d}=C_{d} \frac{1}{2} \rho_{g} v_{g}^{2} \pi r_{d}^{2}
$$

where $C_{d}$ is the drag coefficient, $\rho_{g}$ is the plasma gas density, $v_{g}$ is the gas velocity and $r_{d}$ is the radius of the droplet.

The vertical component of electromagnetic force suitable for the droplet transfer is given by Amson as follows [29]:

$$
F_{e m v}=\frac{\mu_{0} I^{2}}{4 \pi}\left(\frac{r_{d}}{r_{w}}\right)^{2} f
$$

$$
f=\frac{1}{4}-\left(\frac{3}{2}-\ln 4\right)\left(1+\frac{l_{d}}{r_{d}}\right)^{-2}
$$

where $\mu_{0}$ is the permeability in free space, $I$ is the welding current, $r_{d}$ is the radius of the droplet, $r_{w}$ is the radius of the wire and $l_{d}$ is the length of the radius.

Figure 8 illustrates the arc behavior and force distribution for streaming spray transfer and projected spray transfer, separately. The arc area in streaming spray transfer mode with low $\mathrm{CO}_{2}$ content $(5 \%$ or $10 \%)$ is larger than that in projected spray transfer mode with high $\mathrm{CO}_{2}$ content (20\% or $25 \%$ ), which provides the wire tip with more heat. The wire tip is sharper in streaming spray than in projected spray. Considering the similar gas property, the surface tension of the liquid metal is similar and the difference of $F_{\gamma}$ is not distinguishable. According to Eqs. (4) and (5), $F_{e m v}$ in Figure 8(b) is larger than that in Figure 8(a). However,

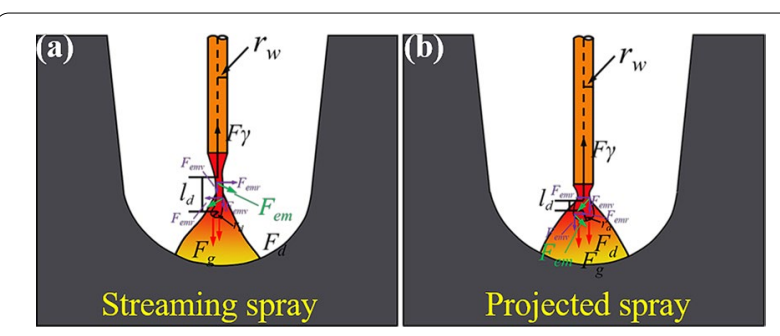

Figure 8 Schematic illustration of arc behavior and forces for (a) streaming spray transfer mode with low $\mathrm{CO}_{2}$ content, and (b) projected spray transfer mode with high $\mathrm{CO}_{2}$ content 
due to the sharper wire tip, the radial component of the electromagnetic force $F_{e m r}$ acting on the droplet in Figure 8(a) is huge, to cause a droplet to subject a strong pinch effect, so the droplet is not able to grow to a massive volume.

The metal transfer under different $\mathrm{O}_{2}$ content is shown in Figure 9. For all shielding gas mixtures, the metal is transferred in pulse streaming spray transfer mode. When $\mathrm{O}_{2}$ increases from $2 \%$ to $5 \%$, a long neck and a taper-shaped wire tip are found in both cases. The long neck is broken at the junction of the neck and the wire tip, and subsequently a big droplet accompanied by some small droplets transfers into the welding pool. And the arc jumping phenomenon accompanies the streaming spray transfer mode. Spatters are seen in Figure 9(b) and (c). The explosive droplet transfer is observed in Figure 10(c) (at $t+2.67 \mathrm{~ms}$ ). This may be ascribed to the received heat in droplet and the pinch effect of large radial electro-magnetic force. The $\mathrm{O}_{2}$ content increases the energy for arc ignition and the heat loss because of its high thermal conductivity, which brings about a greater constriction for the arc. Therefore, the current density becomes higher in arc root, and so does the temperature in arc center. On the other hand, $\mathrm{O}_{2}$ is a kind of active gas that is easy to react with the metal elements in wire. Lots of heat is released by the exothermic reactions. The droplet can be heated to a higher temperature to cause an explosive droplet transfer.

\subsection{Welding Process Stability}

Figure 10 shows the welding current and voltage waveforms for varied contents of $\mathrm{CO}_{2}$ in the shielding gas. When the $\mathrm{CO}_{2}$ content is $5 \%$, the welding current and arc voltage waveforms are not stable at the initial stage of the welding process. Some extremely-high peaks appear at this stage as shown in Figure 10(a). As the $\mathrm{CO}_{2}$ content increases to $10 \%$ or more, only few high peaks appear, which illustrates that the welding process becomes more stable. The high peaks in welding current waveforms represent the occurrence of short-circuit. The valley values (less than $10 \mathrm{~V}$ ) in arc voltage waveforms are caused by the decreased arc length when the droplet is transferred to the welding pool. As shown in Figure 10, with increasing $\mathrm{CO}_{2}$ content, the valley values obviously increase, even when the welding process is are very stable.

Figure 11 displays the welding current and voltage waveforms for varied $\mathrm{O}_{2}$ contents in the shielding gas. The effect of $\mathrm{O}_{2}$ on stabilizing the welding process is more obvious due to its stronger oxidizing property. When about $2 \% \mathrm{O}_{2}$ content is added into the shielding gas, the welding process is similar to that shown in Figure $10(\mathrm{a})$. With $\mathrm{O}_{2}$ content further increasing to $5 \%$ and $10 \%$, the high peaks no longer appear as shown in Figure 11(b) and (c). It is worthwhile to note that the welding process is more effectively stabilized by the same content of $\mathrm{O}_{2}$ than $\mathrm{CO}_{2}$.

Figure 12(a) displays the root-mean-square (RMS) current and voltage of welding in shielding gas with varied $\mathrm{CO}_{2}$ contents. When the $\mathrm{CO}_{2}$ content is in the range
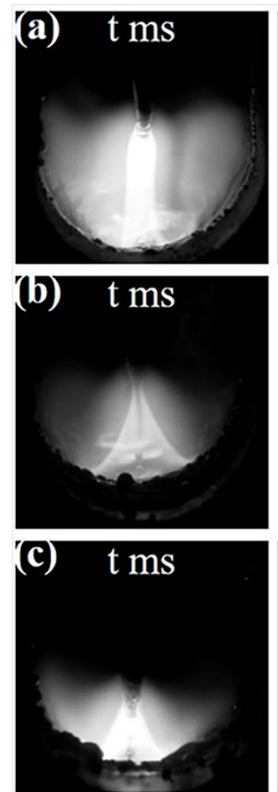
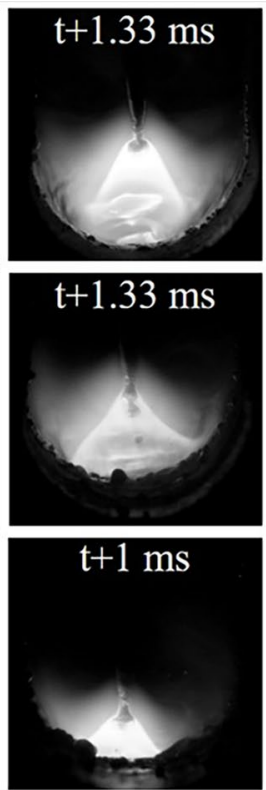
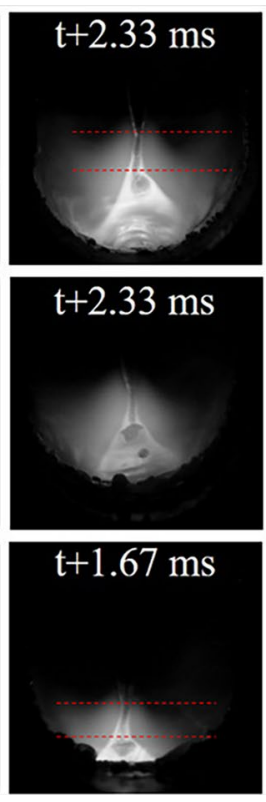
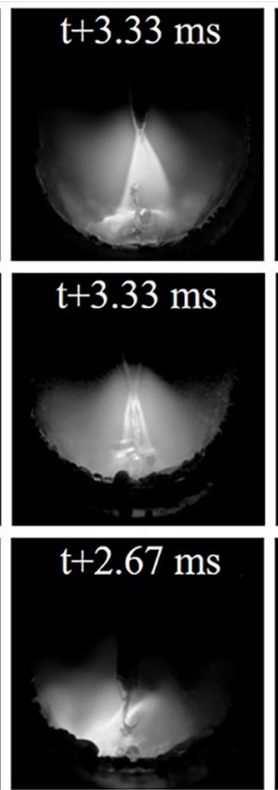
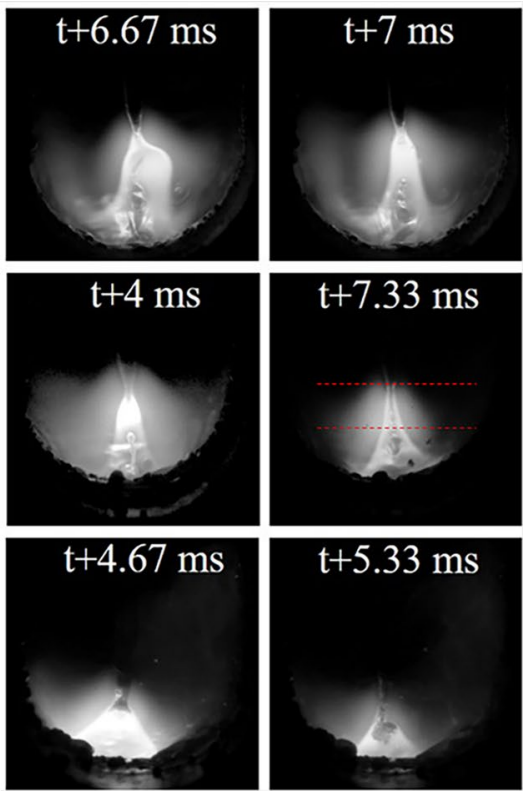

Figure 9 Metal transfer process under shielding of gas mixtures of (a) $\mathrm{Ar}+2 \% \mathrm{O}_{2}, \mathbf{b} \mathrm{Ar}+5 \% \mathrm{O}_{2}, \mathbf{c} \mathrm{Ar}+\mathrm{v} 10 \% \mathrm{O}_{2}$ 

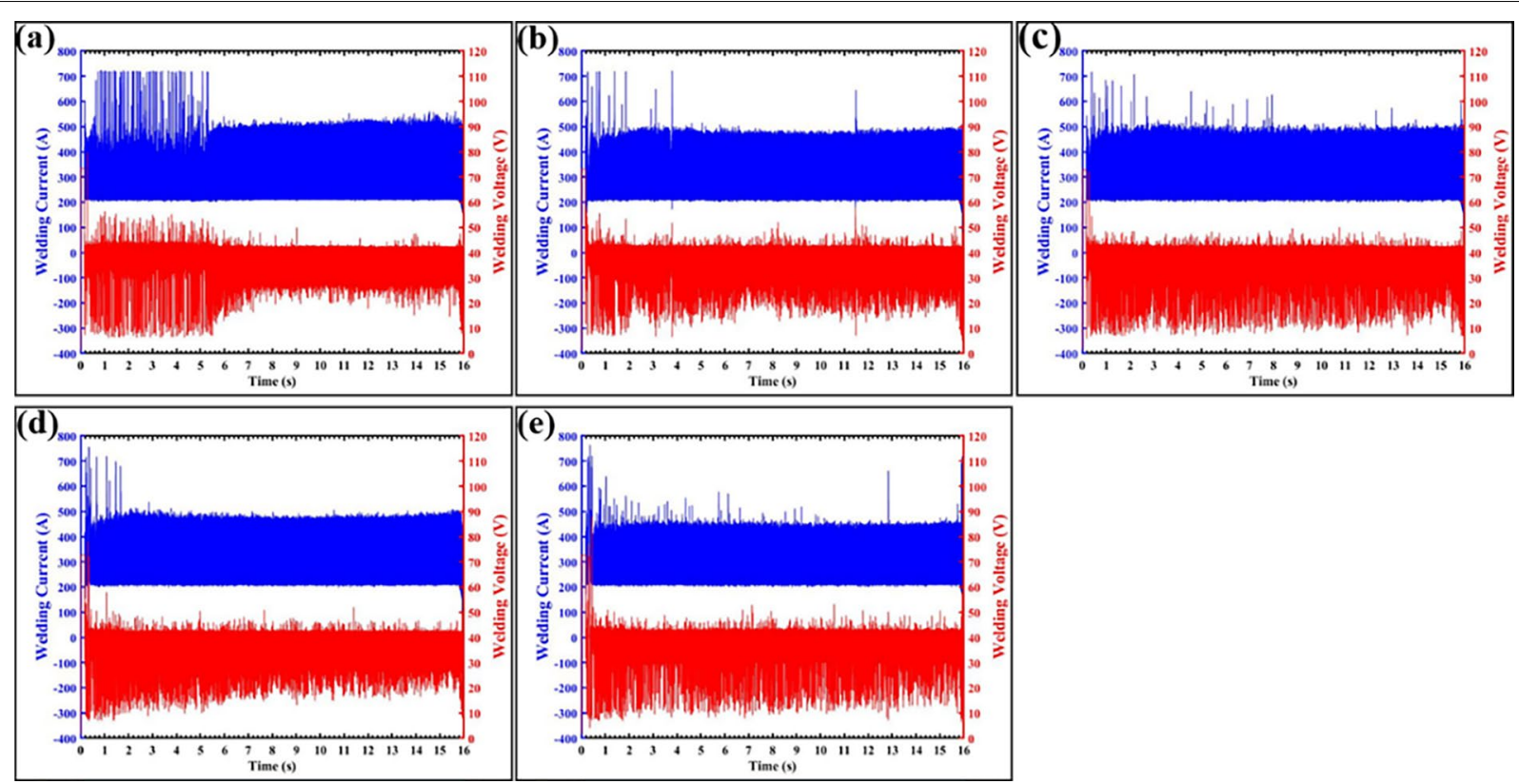

Figure 10 Current and voltage waveforms under shielding of (a) $\mathrm{Ar}+5 \% \mathrm{CO}_{2} ; \mathbf{b} \mathrm{Ar}+10 \% \mathrm{CO}_{2} ; \mathbf{c} \mathrm{Ar}+15 \% \mathrm{CO}_{2} ; \mathbf{d} \mathrm{Ar}+20 \% \mathrm{CO}_{2} ; \mathbf{e} \mathrm{Ar}+25 \% \mathrm{CO}_{2}$
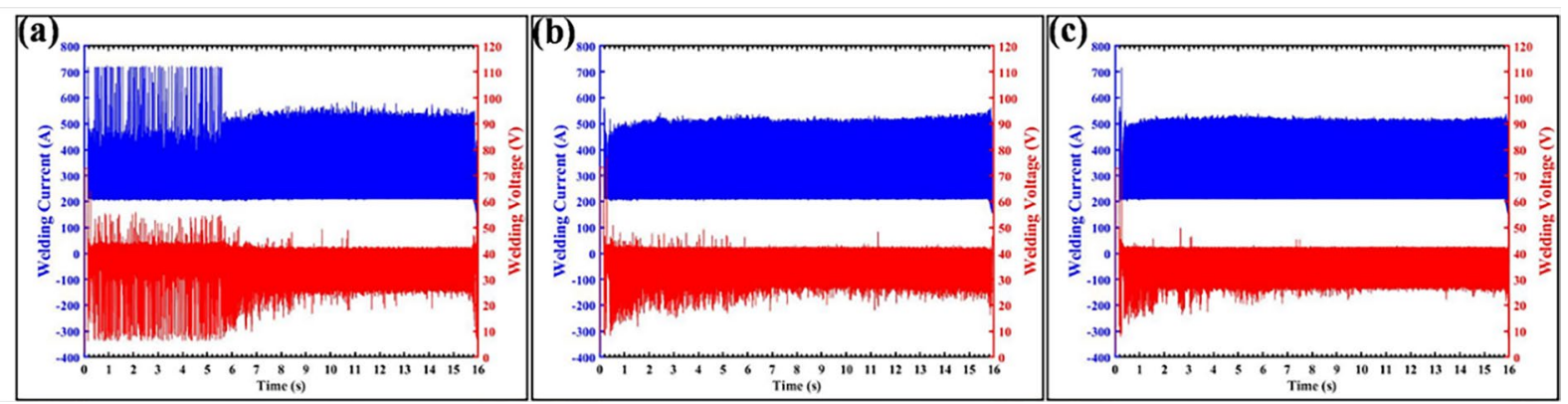

Figure 11 Current and voltage waveforms under shielding of (a) $\mathrm{Ar}+2 \% \mathrm{O}_{2} ; \mathbf{b} \mathrm{Ar}+5 \% \mathrm{O}_{2} ; \mathbf{c} \mathrm{Ar}+10 \% \mathrm{O}_{2}$
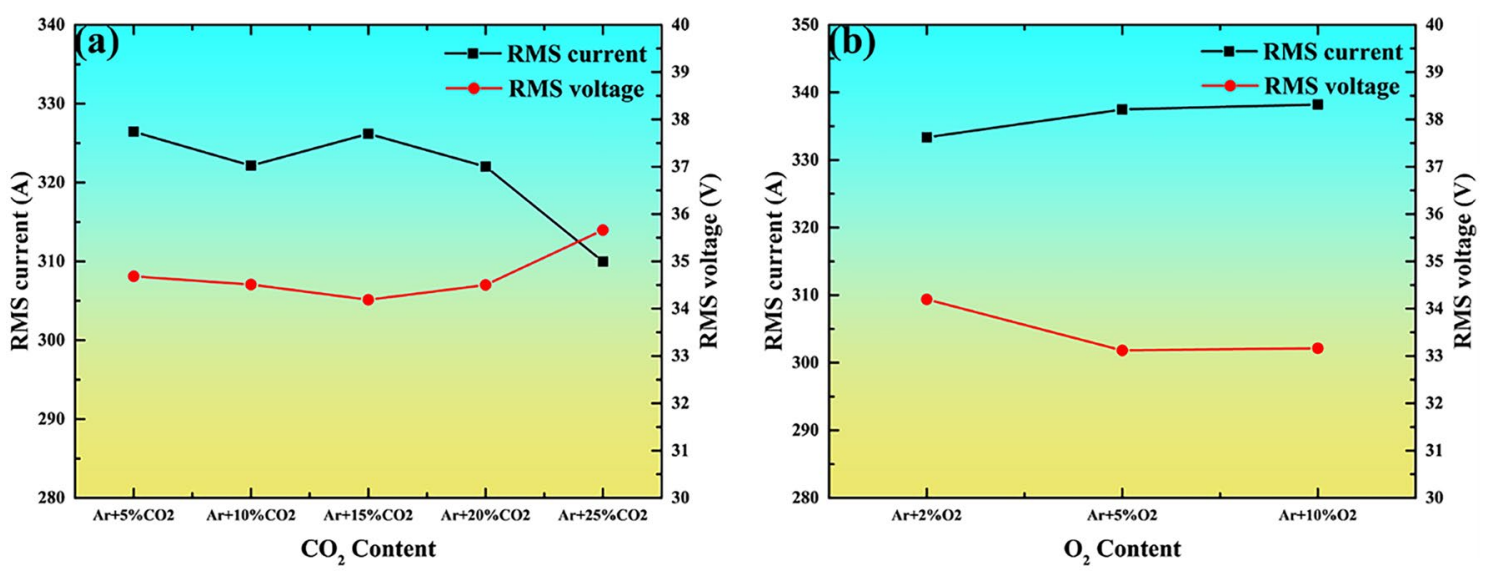

Figure 12 Variations of RMS current and voltage under shielding of gas with (a) varied $\mathrm{CO}_{2}$ contents and $(\mathbf{b})$ varied $\mathrm{O}_{2}$ contents 
from $5 \%$ to $25 \%$, the RMS current shows a slight fluctuation first and then decreases while the RMS voltage first declines mildly and then takes on an obvious rising trend.

When the $\mathrm{CO}_{2}$ content varies from $5 \%$ to $15 \%$, the dissociation of $\mathrm{CO}_{2}$ needs more energy, and meanwhile, the thermal conductivity of shielding gas also increases, which means more conductive energy loss. The increased total energy loss leads to constricting arc profile to make an energy balance. Therefore, the electron density of arc plasma has no significant changes, and so does the RMS current. The variation of arc length improves its potential gradient to maintain the arc stability. Therefore, the RMS voltage changes a little. With the $\mathrm{CO}_{2}$ content further increasing to $25 \%$, the energy loss continues to increase, and thus the ionization degree of shielding gas decreases, which results in the decrease of RMS current. To maintain a stable arc combustion, the RMS voltage increases eventually. Figure 12(b) shows the RMS current and voltage of welding in shielding gas with varied $\mathrm{O}_{2}$ contents. The RMS current slightly increases while the RMS voltage decreases with the increase of the $\mathrm{O}_{2}$ contents. $\mathrm{O}_{2}$ has stronger oxidizability. Lots of heat is released by the exothermic reactions between $\mathrm{O}_{2}$ and the metal elements of wire, as mentioned above. When the $\mathrm{O}_{2}$ content is low, the ionization degree of shielding gas increases with increasing $\mathrm{O}_{2}$ content, leading to increasing RMS current. In addition, the RMS current in shielding gas with certain $\mathrm{O}_{2}$ content is larger than that in shielding gas with same $\mathrm{CO}_{2}$ content. It is proved that the decrease of $\mathrm{CO}_{2}$ could lower the transition current of projected spray transfer or streaming spray transfer. In other words, it is easier to obtain streaming spray transfer or projected spray transfer in the shielding gas with low $\mathrm{CO}_{2}$ content.

\subsection{Weld Bead Formation}

Figure 13 shows the first weld bead appearances and their cross-sections of NG-GMAW under different shielding gases. When the $\mathrm{CO}_{2}$ content is $5 \%$, the weld bead surface is fluctuant, which may result from the random fluctuation of welding pool due to the unstable pulse streaming spray mode at the initial stage. When the $\mathrm{CO}_{2}$ content increases to more than $5 \%$, the weld bead appearance becomes smooth. When the $\mathrm{O}_{2}$ content in the shielding gas gets up to $2 \%$, the weld bead appearance is similar to that for the shielding gas of $\mathrm{Ar}+5 \% \mathrm{CO}_{2}$. In this case, the arc is long and its arc stiffness is relatively low. Hence, a droplet may not directly fall into the welding pool along the axis direction, as it is prone to be influenced by the anode spot force and other forces. When the $\mathrm{O}_{2}$ content is $5 \%$, some slags appear on the surface of the weld, distributing mainly along the centerline. With the $\mathrm{O}_{2}$ content increasing to $10 \%$, there are more slags on the weld surface. It is very difficult to remove the slags in

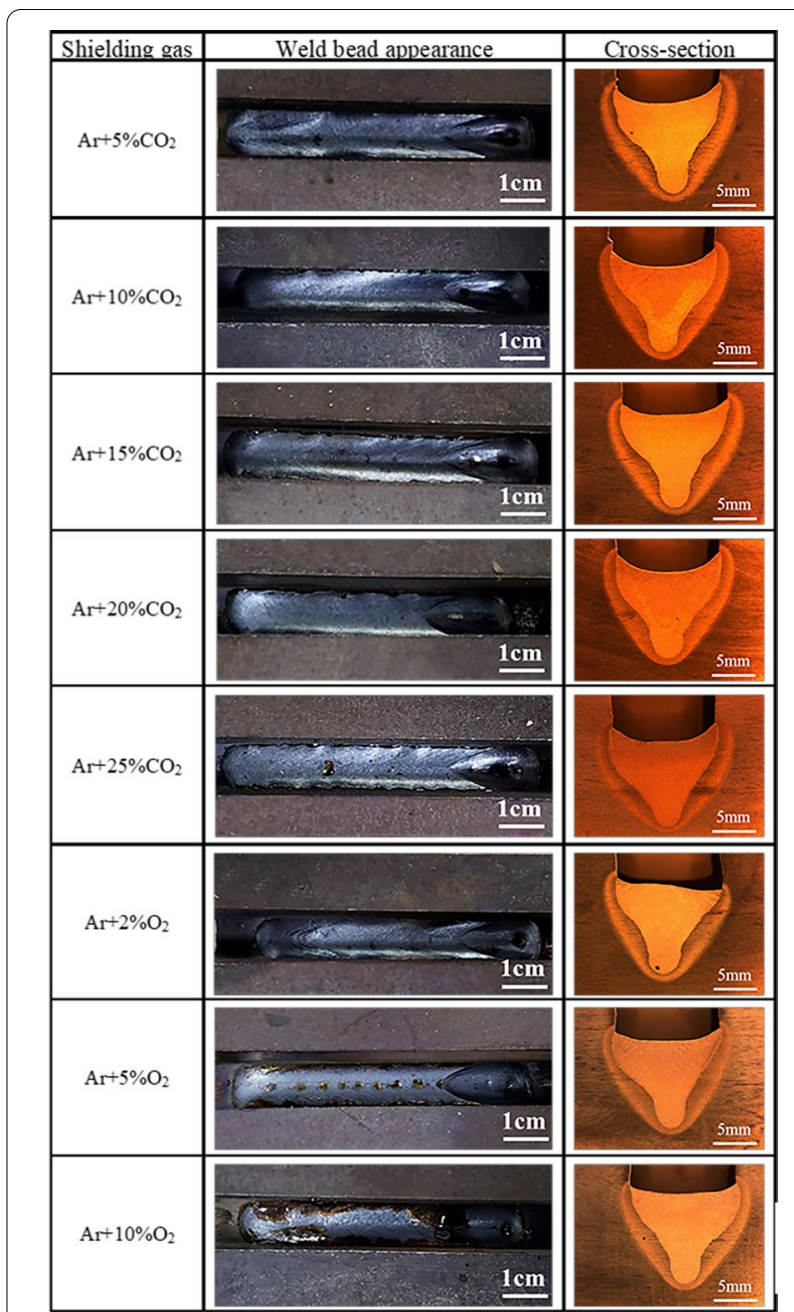

Figure 13 Macrographs of weld appearance and cross-section under different shielding gases

NG-GMAW. Even a few slags on the weld bead surface may cause inclusion defects or lack-of-fusion defects in subsequent multi-pass welding process, which will seriously damage the mechanical properties of the welding joint. Therefore, the shielding gas mixture with $\mathrm{O}_{2}$ content over $5 \%$ is not suggested, although it can greatly improve the arc stability and the welding process.

The finger penetrations are obtained for all the shielding gas mixtures. The weld bead surface is nearly flat and an undercut defect occurs in $\mathrm{Ar}+2 \% \mathrm{O}_{2}$ shielding gas mixture, while the weld bead surfaces in other shielding gas mixtures appear to be concave. There is no lack-ofsidewall-fusion defect, and enough sidewall penetration is obtained for all weld beads. The weld width, the weld penetration and the weld surface concavity obtained in the shielding gases with varied $\mathrm{CO}_{2}$ and $\mathrm{O}_{2}$ contents are presented in Figure 14. Both the weld width and the weld penetration for all shielding gas mixtures are similar. The 

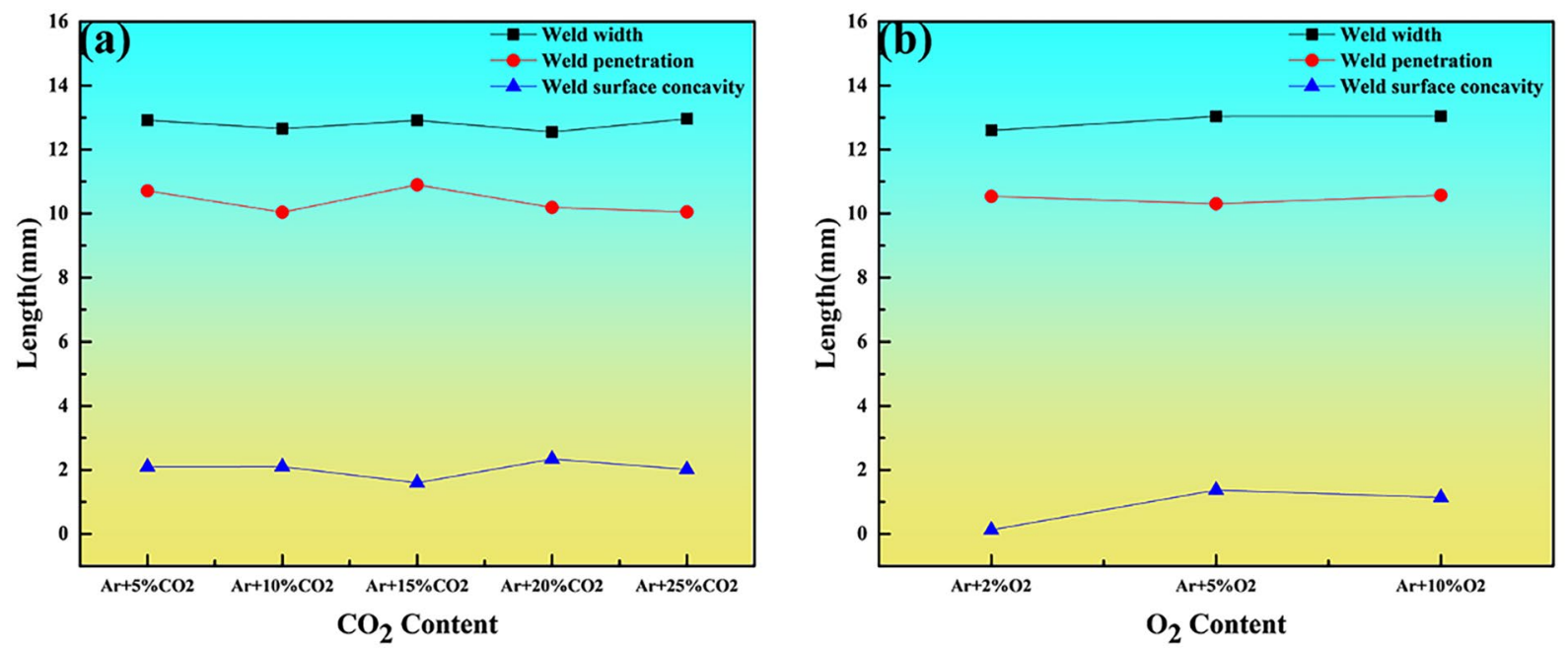

Figure 14 Variations of weld bead width, penetration and surface concavity with different (a) $\mathrm{CO}_{2}$ content and (b) $\mathrm{O}_{2}$ content

weld surface concavity can be evaluated based on the cross-section of the weld beads. It is in the range from 1.0 to $2.0 \mathrm{~mm}$, which means a concave-shape weld bead surface.

The formation of the finger penetration and concaveshape weld bead surface is tightly related with the droplet transfer mode and arc pressure. The streaming spray transfer or spray transfer is the main transfer mode, in which the impact force is large enough to form a finger penetration, despite the relatively small droplet volume. According to Chen and $\mathrm{Wu}$ [30], the impact force of droplet is expressed as follow:

$$
F_{i m p}=\frac{f_{d} m_{d} V_{d}}{\pi R_{d}^{2}}
$$

where $f_{d}$ is the droplet transfer frequency, $m_{d}$ is the mass of the droplet, and $V_{d}$ is the velocity of droplet impinging on the welding pool.

The flow behavior of the welding pool under different droplet transfer mode is shown in Figure 15. The droplet is smaller, and its transfer frequency is higher in streaming spray transfer mode. According to equation (6), the droplet impact force acting on the welding pool is very large, which results in a downward vortex and sunken welding pool surface given in Figure 15(a) and is easy to produce a finger penetration and concave-shape weld bead surface. As shown in Figure 15(b), due to the larger droplet and lower droplet transfer frequency, the droplet impacting force in this transfer mode is much less than that in streaming spray transfer mode. However, the arc length in projected spray transfer mode is smaller. Fan et al reported that the arc pressure increased with the decrease of arc length [31], which means larger arc

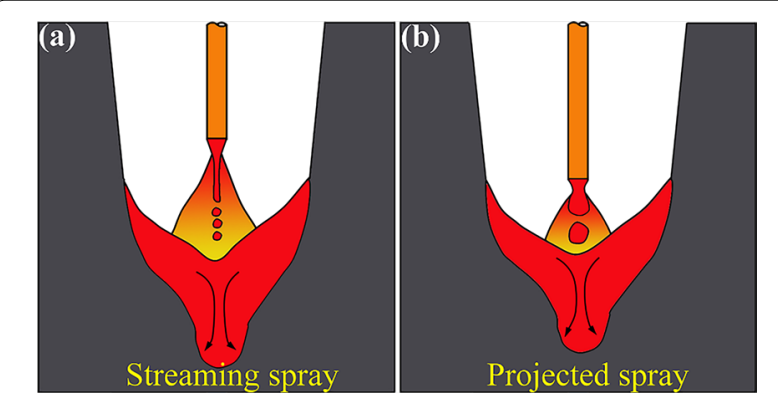

Figure 15 Flow behavior of the welding pool under (a) streaming spray droplet transfer and (b) projected spray droplet transfer

pressure in Figure 15(b), and thus the similar weld formation could form.

\section{Conclusions}

(1) The arc length, width and area all decrease with the increase of $\mathrm{CO}_{2}$ content or $\mathrm{O}_{2}$ content. The thermal pinch effect and increased electromagnetic forces lead to a constricted arc when the $\mathrm{CO}_{2}$ or $\mathrm{O}_{2}$ content is higher. When the $\mathrm{CO}_{2}$ content is in the range of $5 \%-10 \%$ or $\mathrm{O}_{2}$ content is $5 \%$, the arc edge is upward warped at the peak current due to the restrain effect of narrow gap groove.

(2) With the $\mathrm{CO}_{2}$ content in the shielding gas increasing from $5 \%$ to $25 \%$, the droplet transfer mode changes from pulsed streaming spray to pulsed projected spray because of the increased heat loss and arc ignition energy. The droplet transfer mode keeps streaming spray transfer when the $\mathrm{O}_{2}$ content ranges from $2 \%$ to $10 \%$. The streaming spray trans- 
fer is accompanied by the long neck and arc jumping phenomenon.

(3) The welding process stability is improved first and then gets worse with the $\mathrm{CO}_{2}$ content increasing from $5 \%$ to $25 \%$ while it becomes increasingly better and better with the $\mathrm{O}_{2}$ content ranging from $2 \%$ to $10 \%$. The effect of $\mathrm{O}_{2}$ has a more obvious effect on stabilizing the welding process due to its stronger oxidizing property.

(4) A concave weld bead surface is obtained in all shielding gases except $\mathrm{Ar}+2 \% \mathrm{O}_{2}$. The weld bead surface is fluctuant when the $\mathrm{CO}_{2}$ content is $5 \%$ or $\mathrm{O}_{2}$ content is $2 \%$ resulting from the unstable metal transfer and arc behaviors.

\section{Acknowledgements}

Not applicable.

\section{Authors' contributions}

XT developed the idea, analyzed data, co-wrote and revised the paper. GL developed the idea, designed and performed the experiments, analyzed data and wrote the paper. QX performed the experiments. $\mathrm{HC}$ assisted with the experiments. FL assisted with paper revision. All authors read and approved the final manuscript.

\section{Authors' information \\ Guoqiang Liu, born in 1992, is currently a PhD candidate at School of Materials Science and Engineering, Shanghai Jiao Tong University, China. \\ Xinhua Tang, born in 1964, is currently a professor and a PhD supervisor at School of Materials Science and Engineering, Shanghai Jiao Tong University, China. \\ Xu Qi, born in 1995, received his master degree from Shanghai Jiao Tong University, China, in 2019.}

Haichao Cui, born in 1979, is currently an associate senior engineer at School of Materials Science and Engineering, Shanghai Jiao Tong University, China.

Fenggui Lu, born in 1975, is currently a professor and a PhD supervisor at School of Materials Science and Engineering, Shanghai Jiao Tong University, China.

\section{Funding}

No applicable.

\section{Competing interests}

The authors declare no competing financial interests.

\section{Author Details}

'Shanghai Key Laboratory of Materials Laser Processing and Modification, School of Materials Science and Engineering, Shanghai Jiao Tong University, Shanghai 200240, China. ${ }^{2}$ Collaborative Innovation Center for Advanced Ship and Deep-Sea Exploration, Shanghai 200240, China.

Received: 5 May 2020 Revised: 7 January 2021 Accepted: 26 May 2021 Published online: 16 June 2021

\section{References}

[1] CX Zhu, X HTang, Y He, et al. Effect of preheating on the defects and microstructure in NG-GMA welding of 5083 Al-alloy. Journal of Materials Processing Technology, 2018, 251:214-224.

[2] GXXu, L Li, J Y Wang, et al. Study of weld formation in swing arc narrow gap vertical GMA welding by numerical modeling and experiment. The
International Journal of Advanced Manufacturing Technology, 2018, 96(5-8): 1905-1917.

[3] CX Zhu, X H Tang, Y He, et al. Study on arc characteristics and their influences on weld bead geometry in narrow gap GMAW of 5083 Al-alloy. The International Journal of Advanced Manufacturing Technology, 2017 90(9-12): 2513-2525.

[4] Y He, X HTang, C X Zhu, et al. Study on insufficient fusion of NG-GMAW for $5083 \mathrm{Al}$ alloy. The International Journal of Advanced Manufacturing Technology, 2017, 92(9-12): 4303-4313.

[5] CX Zhu, J Cheon, X H Tang, et al. Effect of swing arc on molten pool behaviors in narrow-gap GMAW of 5083 Al-alloy. Journal of Materials Processing Technology, 2018, 259: 243-258.

[6] B Duan, J C Wang, Z H Lu, et al. Parameter analysis and optimization of the rotating Arc NG-GMAW welding process. International Journal of Simulation Modelling, 2018, 17(1): 170-179.

[7] J F Wang, Q J Sun, T Zhang, et al. Arc characteristics in alternating magnetic field assisted narrow gap pulsed GTAW. Journal of Materials Processing Technology, 2018, 54: 254-264.

[8] Y F Meng, G Li, M Gao, et al. Formation and suppression mechanism of lack of fusion in narrow gap laser-arc hybrid welding. The International Journal of Advanced Manufacturing Technology, 2019, 100(9-12): 2299-2309.

[9] Y F Meng, G Li, M Gao, et al. Effects of groove parameters on space constraint of narrow gap laser-arc hybrid welding. Journal of Manufacturing Processes, 2018, 33: 144-149.

[10] XY Cai, C L Fan, S B Lin, et al. Effects of shielding gas composition on arc characteristics and droplet transfer in tandem narrow gap GMA welding. Science and Technology of Welding and Joining, 2017, 22(5): 446-453.

[11] G Q Liu, X H Tang, S Y Han, et al. Influence of interwire angle on undercutting formation and arc behavior in pulsed tandem narrow-gap GMAW. Materials \& Design, 2020, 193:108795.

[12] A Aoki, STashiro, H Kurokawa, et al. Development of novel MIG welding process with duplex current feeding. Journal of Manufacturing Processes, 2019, 47: 74-82.

[13] SW Zhang, J H Sun, M H Zhu, et al. Effects of shielding gases on process stability of $10 \mathrm{CrNi3MoV}$ steel in hybrid laser-arc welding. Journal of Materials Processing Technology, 2019, 270: 37-46.

[14] HY Huang. Effects of shielding gas composition and activating flux on GTAW weldments. Materials and Design, 2009, 30: 2404-2409.

[15] J H Sun, P L Nie, K Feng, et al. The elimination of pores in laser welds of AISI 304 plate using different shielding gases. Journal of Materials Processing Technology, 2017, 248: 56-63.

[16] R Zong, J Chen, C S Wu, et al. Influence of shielding gas on undercutting formation in gas metal arc welding. Journal of Materials Processing Technology, 2016, 234: 169-176.

[17] P Jonsson, A B Murphy, J Szekely. The influence of $\mathrm{O}_{2}$ additions on argonshielded gas metal arc welding processes. Welding Journal-Including Welding Research Supplement, 1995, 74(2): 48s.

[18] L L Wang, F G Lu, H P Wang, et al. Effects of shielding gas composition on arc profile and molten pool dynamics in gas metal arc welding of steels. Journal of Physics D: Applied Physics, 2014, 47(46): 465202.

[19] S Chandra-ambhorn, P Saranyachot. Effect of the $\mathrm{H}_{2}$ content in shielding gas on the microstructure and oxidation resistance of $\mathrm{Fe}-15.7 \mathrm{wt} . \%$ $\mathrm{Cr}-8.5 \mathrm{wt} . \% \mathrm{Mn}$ steel GTA welds. Journal of Materials Processing Technology, 2019, 268: 18-24.

[20] X Y Cai, C L Fan, S B Lin, et al. Effects of shielding gas composition on arc behaviors and weld formation in narrow gap tandem GMAW. The International Journal of Advanced Manufacturing Technology, 2017, 91: 3449-3456.

[21] Y Zhao, X J Shi, KYan, et al. Effect of shielding gas on the metal transfer and weld morphology in pulsed current MAG welding of carbon steel. Journal of Materials Processing Technology, 2018, 262: 382-391.

[22] Y R Wong, S F Ling. An investigation of dynamical metal transfer in GMAW-Effects of argon shielding gas. Journal of Materials Processing Technology, 2014, 214: 106-111.

[23] A B Murphy, C J Arundelli. Transport coefficients of argon, nitrogen, oxygen, argon-nitrogen, and argon-oxygen plasmas. Plasma Chemistry and Plasma Processing, 1994, 14(4): 451-490.

[24] $\vee$ A Nemchinsky. Size and shape of the liquid droplet at the molten tip of an arc electrode. Journal of Physics D: Applied Physics, 1994, 27(7): 1433. 
[25] A Scotti, V Ponomarev, W Lucas. A scientific application oriented classification for metal transfer modes in GMA welding. Journal of Materials Processing Technology, 2012, 212(6): 1406-1413.

[26] Y S Kim, TW Eagar. Analysis of metal transfer in gas metal arc welding. Welding Journal- New York, 1993, 72(6): 269s-278s.

[27] P Sahoo, T Debroy, M J McNallan. Surface tension of binary metal-surface active solute systems under conditions relevant to welding metallurgy. Metallurgical transactions B, 1988, 19(3): 483-491.

[28] S Rhee, E Kannatey-Asibu. Observation of metal transfer during gas metal arc welding. Welding Journal- New York, 1992, 71: 381-386.
[29] J C Amson. Lorentz force in the molten tip of an arc electrode. British Journal of Applied Physics, 1965, 16(8): 1169

[30] J Chen, C S Wu. Numerical analysis of forming mechanism of hump bead in high speed GMAW. Welding in the World, 2010, 54(9-10): 286-291.

[31] H G Fan, Y W Shi. Numerical simulation of the arc pressure in gas tungsten arc welding. Journal of Materials Processing Technology, 1996, 61(3): 302-308.

\section{Submit your manuscript to a SpringerOpen ${ }^{\odot}$} journal and benefit from:

- Convenient online submission

- Rigorous peer review

- Open access: articles freely available online

- High visibility within the field

- Retaining the copyright to your article

Submit your next manuscript at $\boldsymbol{s p r i n g e r o p e n . c o m ~}$ 